\title{
Traumatic brain injury (TBI) outcomes in an LMIC tertiary care centre and performance of trauma scores
}

\author{
Samitha Samanamalee ${ }^{1}$, Ponsuge Chathurani Sigera ${ }^{2,3}$, Ambepitiyawaduge Pubudu De Silva ${ }^{2,3,4}$, \\ Kaushila Thilakasiri², Aasiyah Rashan², Saman Wadanambi ${ }^{5}$, Kosala Saroj Amarasiri Jayasinghe ${ }^{6}$, \\ Arjen M. Dondorp ${ }^{7}$ and Rashan Haniffa ${ }^{2,3,7^{*}}$ [D
}

\begin{abstract}
Background: This study evaluates post-ICU outcomes of patients admitted with moderate and severe Traumatic Brain Injury (TBI) in a tertiary neurocritical care unit in an low middle income country and the performance of trauma scores: A Severity Characterization of Trauma, Trauma and Injury Severity Score, Injury Severity Score and Revised Trauma Score in this setting.

Methods: Adult patients directly admitted to the neurosurgical intensive care units of the National Hospital of Sri Lanka between 21st July 2014 and 1st October 2014 with moderate or severe TBI were recruited.

A telephone administered questionnaire based on the Glasgow Outcome Scale Extended (GOSE) was used to assess functional outcome of patients at 3 and 6 months after injury. The economic impact of the injury was assessed before injury, and at 3 and 6 months after injury.

Results: One hundred and one patients were included in the study. Survival at ICU discharge, 3 and 6 months after injury was $68.3 \%, 49.5 \%$ and $45.5 \%$ respectively. Of the survivors at 3 months after injury, 43 (86\%) were living at home. Only 19 (38\%) patients had a good recovery (as defined by GOSE 7 and 8). Three months and six months after injury, respectively 25 (50\%) and 14 (30.4\%) patients had become "economically dependent". Selected trauma scores had poor discriminatory ability in predicting mortality.

Conclusions: This observational study of patients sustaining moderate or severe TBI in Sri Lanka (a LMIC) reveals only $46 \%$ of patients were alive at 6 months after ICU discharge and only 20\% overall attained a good (GOSE 7 or 8 ) recovery. The social and economic consequences of TBI were long lasting in this setting. Injury Severity Score, Revised Trauma Score, A Severity Characterization of Trauma and Trauma and Injury Severity Score, all performed poorly in predicting mortality in this setting and illustrate the need for setting adapted tools.
\end{abstract}

Keywords: Traumatic brain injury, Low middle income country, Economic outcome, Social outcome, Functional outcome, ICU mortality

\footnotetext{
* Correspondence: rashan@nicslk.com

${ }^{2}$ Network for Improving Critical Care Systems and Training, 2nd Floor, YMBA

Building, Colombo 08, Sri Lanka

${ }^{3}$ National Intensive Care Surveillance, Quality Secretariat Building, Castle

Street Hospital for Women, Colombo 08, Sri Lanka

Full list of author information is available at the end of the article
}

\section{Ciomed Central}

(c) The Author(s). 2018 Open Access This article is distributed under the terms of the Creative Commons Attribution 4.0 International License (http://creativecommons.org/licenses/by/4.0/), which permits unrestricted use, distribution, and reproduction in any medium, provided you give appropriate credit to the original author(s) and the source, provide a link to the Creative Commons license, and indicate if changes were made. The Creative Commons Public Domain Dedication waiver (http://creativecommons.org/publicdomain/zero/1.0/) applies to the data made available in this article, unless otherwise stated. 


\section{Background}

Traumatic Brain Injury (TBI) is a major public health problem worldwide resulting in death and disability, especially of young and economically active individuals [1-3]. Neuropsychiatric consequences are common among TBI patients $[4,5]$. TBI is greatest in low and middle income countries (LMIC), where $85 \%$ of the world's population live [6]. In comparison to patients in highincome countries (HIC), limited data indicates that LMIC patients have over twice the odds of dying following severe TBI [6] and have a greater degree of disability.

Trauma scoring systems such as A Severity Characterization of Trauma (ASCOT), Trauma and Injury Severity Score (TRISS), Injury Severity Score (ISS) and Revised Trauma Score (RTS) enable benchmarking of services, quality assurance and research [7-10]. These and other similar models are usually developed for HIC settings and are infrequently validated in LMICs. Healthcare facilities, access to healthcare, varied case-mix and missing data can influence the performance of these models. Trauma or medical registries, which report outcome data, enable benchmarking of services (using probability of survival models such as ASCOT), and enable research are uncommon in LMICs [11]. It is thus important to validate and if necessary, adapt such models to the local setting.

Superior outcomes in HIC following TBI are most likely due to a combination of expert multidisciplinary efforts in pre hospital, hospital (including neurosurgical and critical care), rehabilitation services, and well developed support networks and quality improvement efforts [6]. In LMICs access to advanced neurosurgical and critical care services is limited and competition for these services remains high [12]. Follow up services facilitating long term rehabilitation, and requiring considerable equipment and manpower, are less well developed, resulting in treatment outcomes and complications being harder to ascertain and limiting improvement efforts. Similar to other critically unwell patients in LMIC settings, long-term outcomes for TBI patients, including functional status, patient independence and economic impact after TBI are not known in Sri Lanka and not widely known for other LMICs [6, 13, 14]. National Hospital of Sri Lanka (NHSL) is the largest, and one of only two tertiary care neurosurgical centres in the country. The neurotrauma (NT) unit here has two dedicated neurotrauma intensive care units (ICUs) containing seven beds each.

This paper evaluates post-ICU outcomes of patients admitted with moderate and severe TBI to a tertiary neurocritical care unit in an LMIC and the performance of RTS, ASCOT, ISS and TRISS in this setting.

\section{Methods}

Consecutive adult patients (over 16 years of age) directly admitted to the neurosurgical intensive care units of the NHSL between 21st July 2014 and 1st October 2014 with moderate or severe TBI were recruited for this study. The selection of study duration was pragmatic. Severe TBI was defined as a Glasgow Coma Scale (GCS) of $<9$ and moderate TBI was by a GCS of $9-12$ at hospital admission $[15,16]$. Patients who were transferred from other centres and any patients who had no contactable relatives in order to provide a contact telephone number and who were unable to communicate were excluded.

Patients were recruited to the study while being treated in the ICUs. Informed verbal consent was obtained from those patients who were adjudged to have capacity. Capacity was determined independently by the ICU team caring for the patient. If patients did not have capacity, assent was obtained from the Next Of Kin (NOK) and the study details were explained to them. Where assent was obtained and patient thereafter recovered to have capacity, informed written consent was obtained from patients. Any patients who subsequently declined consent were to have their data retrospectively removed.

Data such as patient age, gender, level of education, marital status, and mechanism of injury were gathered by a data collector during ICU stay from the patient or the next of kin. ICU length of stay was collected after ICU discharge. Medical data extracted from case notes included nature and extent of injuries, CT brain findings, GCS scores, respiratory rate and systolic blood pressure on admission. RTS, ISS, TRISS and ASCOT scores were calculated $[7,17]$.

A telephone administered questionnaire based on the Glasgow Outcome Scale Extended (GOSE) scale [18-21] was used to assess functional outcome of patients at 3 and 6 months after injury. The questionnaire could be completed independently by the patient, assisted by a adult living with the patient or completed by an adult living with the patient if patient was unable to communicate.

The GOSE scale rates the patient status into 8 categories: dead, vegetative state, lower severe disability, upper severe disability, lower moderate disability, upper moderate disability, lower good recovery, and upper good recovery. In order to aid analysis, functional outcome was divided into 3 groups based on GOSE scores; dead/vegetative (GOSE 1,2), disability (GOSE 3,4,5,6) and good recovery (GOSE 7,8).

The economic impact of the injury was assessed by the extent of economic dependence of the patient and their family, before injury, and at the time of the interviews ( 3 and 6 months after injury). An adapted tool from Griffiths et al was utilised with the exception of a question on specifics regarding family income which was considered too sensitive to include [22]. Patients' 
employment status before injury and at the time of the interviews was also assessed [6].

Data was analysed using Stata 13 [23]. Chi-Square test was used to compare categorical variables and Ordinal Logistic Regression (OLR) was used for continuous variables. Non-parametric median test was used to analyse factors related to ICU length of stay. Discriminatory ability of RTS, ISS, ASCOT and TRISS for 30-day mortality was evaluated using the Area Under the Receiver Operator Characteristic (AUROC) and calibration for the latter two scores were assessed by the Hosmer-Lemeshow C-statistic.

\section{Results}

101 patients with TBI admitted to the NHSL neurosurgical unit were included in the study. 17 patients provided direct consent, 84 patients were recruited after assent from relatives and a further 16 patients were excluded due to consent or assent being declined.

$83(82 \%)$ patients were male. Ages ranged from 16 to 83 years with a mean age of 41.67 (SD 17.47) years. The dataset required for scoring system calculation was complete except for $3(3.0 \%)$ patients who had no respiratory rate recorded and $18(17.8 \%)$ did not have the blunt/penetrating nature of their injury recorded. Eighty-two of these patients (81.2\%) had completed at least secondary education though only two patients had attended university. Just over $2 / 3^{\text {rds }}(68,67.3 \%)$ of the patients were after RTAs while nearly everyone else (25 patients, 24.8\%) were subsequent to falling from a height. When categorised by GCS scores on admission, 63 patients had severe TBI and 38 had moderate TBI. The mean ASCOT score was 29.2\% (SD 23.7). Patient characteristics and summary values for the other three trauma scores are further summarised in Table 1.

Survival at ICU discharge, 3 and 6 months after injury was $68.3 \%$ (69 patients), 49.5\% (50 patients) and 45.5\% (46 patients) respectively. 7 (6.9\%) patients were lost to follow-up as they were not contactable via the telephone numbers obtained. There was no significant difference between moderate and severe TBI (as per GCS) groups and survival at ICU discharge $(p=0.180)$, survival at 3 months $(p=0.308)$ or survival at 6 months $(p=0.220)$. Similarly, there was no significant difference between patients after RTA and those after falls, when survival at ICU discharge $(p=0.501), 3$ months $(p=0.502)$ and 6 months $(p=0.847)$ were considered. There was also no significant association between length of ICU stay and moderate or severe TB $(p=0.411)$ or between Road Traffic Accident (RTA) and fall $(p=0.777)$.

Of the patients who were alive at 3 months after injury, 43 (86\%) were living at home while the remainder were in rehabilitation centres or in hospital. Eighty percent (40 patients) could complete the study questionnaire unaided whereas $89 \%$ (41 patients) could do so 6 months after injury. Only 2 questionnaires at both 3 and 6 months after injury were jointly completed by both a patient and adult NOK. On behalf of $8(16 \%)$ and $5(11 \%)$ patients all information was provided by an adult NOK at 3 months and 6 months, respectively.

Further outcome data are shown in Table 2. The number of patients who had a good recovery (as defined by GOSE 7 and 8) at 3 and 6 months after injury was 19 and 20 respectively. Functional outcomes at 3 and 6 months were not significantly associated with severity of injury as characterised by GCS (9-12 and less than 9, $p=0.524$ and 0.294 , respectively). There was no significant difference between functional outcomes at 3 and 6 months and mechanism of injury (RTA and fall, $p$ $=0.555,0.793)$. Further, there was no significant association between age and functional outcome at 3 months $(p=0.782$, OR $=1)$ and 6 months $(p=0.621$, OR $=1)$.

Twenty one patients were unemployed 3 months after injury with 17 patients remaining unemployed at 6 months. One patient moved from full-time to parttime employment. There was a significant difference between moderate/severe TBI and change in employment status at 3 months $(p=0.030)$ but not at 6 months $(p=0.141)$. There was no significant difference between patients after RTA and those after falls with change in employment status due to injury at either $3(p=0.734)$ or 6 months $(p=0.138)$.

Three months after injury, 25 patients had become "economically dependent" with 14 patients remaining economically dependent at 6 months. Similarly, 17 families who were "economically independent" prior to the event became dependent and 10 families were still dependent at 6 months. There was no significant difference between patients who had a moderate or severe injury and those who became economically dependent at 3 or 6 months $(p=0.076,0.177)$. There was also no significant difference between mechanism of injury (RTA/ Fall) and subsequent economic dependence of patients at 3 or 6 months $(p=0.182,0.712)$.

The performances of all 4 severity scores for predicting 30-day mortality are tabulated in Table 3.

\section{Discussion}

Moderate and severe TBI are catastrophic events in this LMIC setting, predominantly affecting non-university educated young men resulting in long-term adverse sequelae; $50 \%$ survival at 3 -months; only $19 \%$ having a good recovery (GOSE 7 and 8) at 6 months; $50 \%$ of survivors and $34 \%$ families being economically dependent at 3 months. Outcomes for moderate TBI are poorer than those reported in a study carried out in several LMICs, although outcomes for severe TBI in this dataset are similar to those reported in the same study 
Table 1 Patient characteristics and summary values for the trauma scores. Values are number (percentage), mean (SD) and range

\begin{tabular}{|c|c|c|c|c|c|}
\hline & moderate injury $(n=38)$ & severe injury $(n=63)$ & total $(n=101)$ & RTA $(n=68)$ & Fall $(n=24)$ \\
\hline \multicolumn{6}{|l|}{ Gender } \\
\hline Male (\%) & $31(82)$ & $52(83)$ & $83(82)$ & $54(79)$ & $22(92)$ \\
\hline Female(\%) & $7(18)$ & $11(17)$ & $18(18)$ & $14(21)$ & $2(8)$ \\
\hline \multicolumn{6}{|l|}{ Age } \\
\hline Range & $19-83$ & $16-79$ & $16-83$ & $16-83$ & $28-78$ \\
\hline Mean (SD) & $43.86(16.85)$ & $40.46(17.56)$ & $41.67(17.47)$ & $38.23(17.54)$ & 49.92(15.47) \\
\hline \multicolumn{6}{|l|}{ Marital status } \\
\hline Married(\%) & $31(82)$ & $39(62)$ & $70(69)$ & $42(62)$ & $21(88)$ \\
\hline Unmarried(\%) & $5(13)$ & $19(30)$ & $24(24)$ & $21(31)$ & $1(4)$ \\
\hline Divorced(\%) & $1(2)$ & $3(4)$ & $4(4)$ & $3(4)$ & $1(4)$ \\
\hline Widowed(\%) & $1(2)$ & 2(3) & $3(3)$ & $2(3)$ & $1(4)$ \\
\hline \multicolumn{6}{|l|}{ Education level } \\
\hline No formal education & $3(8)$ & 2(3) & $5(5)$ & $1(1)$ & $3(13)$ \\
\hline Primary education & $5(13)$ & $5(8)$ & $10(10)$ & $7(10)$ & $2(8)$ \\
\hline Secondary Education & $28(74)$ & $54(86)$ & $82(81)$ & $57(84)$ & $18(75)$ \\
\hline Degree & $(0)$ & 2(3) & $2(2)$ & $2(3)$ & $0(0)$ \\
\hline \multicolumn{6}{|l|}{ ASCOT score (\%) } \\
\hline ASCOT Mean(SD) & $0.90(0.06)$ & $0.61(0.22)$ & $0.72(0.23)$ & $0.72(0.22)$ & $0.67(0.25)$ \\
\hline TRISS Mean(SD) & $0.97(0.02)$ & $0.86(0.14)$ & $0.90(0.12)$ & $0.91(0.11)$ & $0.86(0.16)$ \\
\hline RTS Mean(SD) & $6.81(0.24)$ & $4.53(0.84)$ & $5.39(1.30)$ & $5.34(1.30)$ & $5.30(1.37)$ \\
\hline ISS Mean(SD) & $6.87(4.41)$ & $5.57(4.69)$ & $6.06(4.61)$ & $6.09(4.02)$ & $6.00(5.08)$ \\
\hline \multicolumn{6}{|l|}{ GCS } \\
\hline$<9$ & $0(0)$ & $63(100)$ & $63(62)$ & $44(65)$ & $15(63)$ \\
\hline 9-12 score & $38(100)$ & $0(0)$ & $38(38)$ & $24(35)$ & $9(38)$ \\
\hline \multicolumn{6}{|l|}{ Mechanism of injury } \\
\hline RTA & $24(63)$ & $44(70)$ & $68(67)$ & $68(100)$ & $0(0)$ \\
\hline Fall & $9(24)$ & $15(24)$ & $24(24)$ & $0(0)$ & $24(100)$ \\
\hline Other & $5(13)$ & $4(6)$ & $9(9)$ & $0(0)$ & $0(0)$ \\
\hline \multicolumn{6}{|l|}{ Length of ICU stay(days) } \\
\hline Median(IQR) & $6(8)$ & $5(6)$ & $6(8.75)$ & $6(8)$ & $5.5(24)$ \\
\hline Range & $1-91$ & $0-122$ & $0-122$ & $1-95$ & $0-122$ \\
\hline
\end{tabular}

[6]. However, mortality rates, both pre and post discharge, for severe TBI are poor when compared with mortality rates from studies carried out in other LMICs $[24,25]$.

This study demonstrates the feasibility of telephone follow-up in patients with moderate and severe TBI admitted to a tertiary neuro-critocal care unit in this LMIC setting. There is now widespread recognition, almost exclusively from research in HIC, on the importance of patient centered post-discharge outcomes such as quality of life measures and economic impact to the individual and family, in addition to ICU or hospital survival, when evaluating critical care services [26]. There are obvious logistical difficulties in determining post-ICU outcomes in LMICs, which impair the evaluation of the effectiveness of scarce critical care services, especially in terms of a return to pre-morbid status and financial independence. The relatively minimal loss to follow-up of TBI patients in this study, albeit in a small sample, may provide insights when developing a methodology for routinely evaluating post-discharge outcomes, especially if paired with a medical registry tracking performance of critical care units $[27,28]$. This study also demonstrates the feasibility of recruiting patients to an observational study in LMICs with assent from NOK where the patient is unable to consent, with the proviso of retrospective withdrawal. Missing data, another common problem in acute care settings in LMIC, was relatively minimal as 
Table 2 Outcome of patients: survival status, functional outcome and economic impact at ICU discharge, 3 months and 6 months after injury. Values are number (percentage)

\begin{tabular}{|c|c|c|c|c|c|}
\hline & $\begin{array}{l}\text { moderate injury } \\
(n=38)\end{array}$ & $\begin{array}{l}\text { severe injury } \\
(n=63)\end{array}$ & $\begin{array}{l}\text { total } \\
(n=101)\end{array}$ & $\begin{array}{l}\text { RTA } \\
(n=68)\end{array}$ & $\begin{array}{l}\text { Fall } \\
(n=24)\end{array}$ \\
\hline \multicolumn{6}{|l|}{ Survival status at ICU discharge } \\
\hline Survived & $29(76)$ & $40(63)$ & $69(68)$ & $46(68)$ & $18(75)$ \\
\hline Died & $9(24)$ & $23(37)$ & $32(32)$ & $22(32)$ & $6(25)$ \\
\hline \multicolumn{6}{|l|}{ Survival status at 3 months after discharge } \\
\hline Survived & $21(55)$ & $29(46)$ & $50(50)$ & $32(47)$ & $13(54)$ \\
\hline Died & $14(37)$ & $30(48)$ & $44(43)$ & $31(46)$ & $9(38)$ \\
\hline Could not be contacted & $3(10)$ & $4(6)$ & $7(6.9)$ & $5(11)$ & $2(8)$ \\
\hline \multicolumn{6}{|l|}{ Survival status at 6 months after discharge } \\
\hline Survived & $20(52)$ & $26(41)$ & $46(46)$ & $30(44)$ & $11(46)$ \\
\hline Died & 15(39) & $33(52)$ & $48(48)$ & $33(48)$ & $11(46)$ \\
\hline Could not be contacted & $3(9)$ & $4(6)$ & $7(6.9)$ & $5(11)$ & $2(8)$ \\
\hline \multicolumn{6}{|l|}{ Functional outcome at 3 months after discharge } \\
\hline Dead/Negetative (GOSE 1,2) & $16(42)$ & $33(52)$ & $49(49)$ & $36(53)$ & 9(38) \\
\hline Disability (GOSE 3,4,5,6) & 10(26) & $16(25)$ & $26(26)$ & $17(25)$ & 7(29) \\
\hline Good Recovery (GOSE 7,8) & $9(24)$ & $10(16)$ & 19(19) & $10(15)$ & $6(25)$ \\
\hline \multicolumn{6}{|l|}{ Functional outcome at 6 months after discharge } \\
\hline Dead/Negetative (GOSE 1,2) & $16(42)$ & $36(57)$ & $52(51)$ & $37(54)$ & $11(46)$ \\
\hline Disability (GOSE 3,4,5,6) & 9(24) & $13(21)$ & $22(22)$ & $15(22)$ & $5(21)$ \\
\hline Good Recovery (GOSE 7,8) & $10(26)$ & $10(16)$ & $20(20)$ & $11(16)$ & $6(25)$ \\
\hline \multicolumn{6}{|l|}{ Economic impact at 3 months after discharge } \\
\hline Patients who became economically dependent after injury & $7(33)$ & $18(62)$ & $25(50)$ & $18(56)$ & 6(46) \\
\hline Families economically dependent after patient injury & $3(14)$ & $14(48)$ & $17(34)$ & $10(31)$ & $5(38)$ \\
\hline Patients with change in employment status due to injury & $8(38)$ & $20(69)$ & $28(56)$ & $19(59)$ & 7(54) \\
\hline \multicolumn{6}{|l|}{ Economic impact at 6 months after discharge } \\
\hline Patients who became economically dependent after injury & $4(20)$ & 10(38) & 14(30) & $10(33)$ & $3(27)$ \\
\hline Families economically dependent after patient injury & $2(10)$ & $8(31)$ & $10(22)$ & $6(20)$ & $3(27)$ \\
\hline Patients with change in employment status due to injury & $5(25)$ & $12(46)$ & $17(37)$ & $13(43)$ & $2(18)$ \\
\hline
\end{tabular}

data was prospectively gathered by a doctor (investigator) visiting the ICU daily and as these scores do not require often expensive and logistically difficult invasive tests. There is some evidence that non-trauma specific prognostic models such as Acute Physiology and Chronic Health Evaluation (APACHE) II and III have at

Table 3 Performance of trauma severity scores in predicting 30-day mortality. Values are number (upper 95\% Cl, lower 95\% Cl), C-statistic and $p$ value

\begin{tabular}{llcc}
\hline & $\begin{array}{l}\text { ROC AUC (upper 95\% Cl, } \\
\text { lower 95\% Cl) }\end{array}$ & $\begin{array}{l}\text { Hosmer Lemeshow } \\
\text { C-statistic }\end{array}$ & $\mathrm{HL} p$-value \\
\hline ASCOT & $0.62(0.51,0.73)$ & 7.49 & 0.4853 \\
TRISS & $0.67(0.56,0.78)$ & 15.83 & 0.0449 \\
RTS score & $0.53(0.41,0.65)$ & & \\
ISS score & $0.46(0.36,0.56)$ & & \\
\hline
\end{tabular}

least comparable performance in predicting outcomes in TBI patients [29]. Our group has previously demonstrated the difficulty of missing values in such models in this setting and data for these models were not gathered in this instance [30].

In this study, all four trauma scores had unsatisfactory discriminatory ability when predicting mortality despite relatively complete datasets. The poor performance of the scoring systems cannot thus be explained by gaps in the dataset, a known problem in critical care datasets from LMICs. Of note, both ASCOT and TRISS had acceptable (and non-statistically significant) calibration, most likely as a consequence of the test having lower power due to the small sample sizes, and not necessarily an indication of a good fit, necessitating caution when interpreting such measures [31]. Overall study findings are a reminder that tools and 
classifications developed for HIC settings may not be directly transferable to LMIC settings without prior validation and adaptation. Further research is required, especially if facilitated by medical registries, which will enable the development and continued adaptation of setting adapted tools and comparison with general prognostic models such as APACHE II.

The long-term sequelae of moderate to severe TBI, to the individual, families and consequently to wider society in this setting are striking. In contrast to previous reports, there were no statistically significant differences in the relatively high mortality or morbidity outcomes between moderate and severe TBI patients [3, 32, 33]. However, this lack of predictive power of the GCS score has been reported in other studies. Possible explanations include the influence of more aggressive pre hospital treatment obscuring GCS and causing difficulties in obtaining a valid neurological assessment during the first $24 \mathrm{~h}$ after trauma $[34,35]$. In addition, this study did not consider the pre-hospital care provided to these patients, the adequacy of the hospital resuscitation efforts, features of ICU care provided and features of post-ICU hospital stay. Efforts to improve hospital outcomes after TBI in this setting will need to focus on these important aspects of care with potential for improvement. Furthermore, this study did not investigate causes of death, specific complications (eg. pressure ulcers, deep vein thrombosisetc), extent of available support services or specific difficulties (eg. travel to hospital for physiotherapy) encountered by patients and their families. Research to explore these factors, with a view to remedial measures and an evaluation of the effectiveness of such measures in this setting are an urgent requirement. The long-term consequences reinforce the importance of preventive measures, especially for RTAs and falling from a height.

This is a single centre study with a small number of patients. This study did not gather details of ICU or post-ICU treatment received by these patients. Generalisability across other settings in Sri Lanka will become possible with ongoing efforts related to an ICU registry. The economic and employment evaluations were not performed by validated tools and highlight the requirement to develop validated and practical tools for use in this setting. Possibilities of bias due to loss to follow-up (6.9\%) and due to NOK assisting or completing the questionnaire for a minority of patients need to be noted.

\section{Conclusions}

This observational study of patients sustaining moderate or severe TBI in Sri Lanka (a LMIC) reveals only $46 \%$ of patients were alive at 6 months after ICU discharge and only $20 \%$ overall having a good (GOSE 7 or 8 ) recovery. The social and economic consequences of TBI were long lasting in this setting. ISS, RTS, ASCOT and TRISS all performed poorly in predicting mortality in this setting and illustrate the need for setting adapted tools.

\section{Abbreviations \\ APACHE: Acute Physiology And Chronic Health Evaluation; ASCOT: A Severity Characterization Of Trauma; AUROC: Area Under the Receiver Operator Characteristic; GCS: Glasgow Coma Scale; GOSE: Glasgow Outcome Scale Extended; HICs: High Income Countries; ICU: Intensive Care Unit; ISS: Injury Severity Score; LMIC: Low and Middle Income Countries; NHSL: National Hospital of Sri Lanka; NOK: Next Of Kin; NT: Neuro Trauma; RTA: Road Traffic Accident; RTS: Revised Trauma Score; TBI: Traumatic Brain Injury; \\ TRISS: TRauma and Injury Severity Score}

\section{Acknowledgements}

The authors acknowledge the support given by Ms. Abi Beane and the staff at NTICUs at NHSL, Sri Lanka.

\section{Competing interests.}

The authors declare that they have no competing interests.

\section{Funding}

The study was supported by the Network for Improving Critical care Systems and Training (NICST) and the Mahidol Oxford Tropical Medicine Research Unit (MORU), Thailand.

Availability of data and materials.

The datasets used and analysed during the current study are available from the corresponding author on reasonable request.

\section{Authors' contributions.}

SS and PCS came up with the research idea. All authors contributed to the development of the methods. SS, SW and KT conducted the data collection. AR, APDS, PCS, KSAR, AMD and RH conducted analysis. All authors contributed to interpreting the analysis. All authors contributed to the writing of the final manuscript. All authors read and approved the final manuscript.

Consent for publication.

Not applicable

Ethics approval and consent to participate.

Ethical review was obtained from the ethics review committee of the University of Colombo (PGDHD/13/13).Informed written consent was obtained from patients.

\section{Publisher's Note}

Springer Nature remains neutral with regard to jurisdictional claims in published maps and institutional affiliations.

\footnotetext{
Author details

${ }^{1}$ Health Education Bureaue, No.2, Kynsey Road, Colombo 08, Sri Lanka. ${ }^{2}$ Network for Improving Critical Care Systems and Training, 2nd Floor, YMBA Building, Colombo 08, Sri Lanka. ${ }^{3}$ National Intensive Care Surveillance, Quality Secretariat Building, Castle Street Hospital for Women, Colombo 08, Sri Lanka. ${ }^{4}$ Intensive Care National Audit \& Research Centre, No. 24, High Holborn, London WC1V 6AZ, UK. ${ }^{5}$ National Hospital of Sri Lanka, Colombo 10, Sri Lanka. ${ }^{6}$ Faculty of Medicine, University of Colombo, No. 25,Kynsey Rd, Colombo 08, Sri Lanka. ${ }^{7}$ Mahidol Oxford Tropical Medicine Research Unit, Faculty of Tropical Medicine, Mahidol University, 3/F, 60th Anniversary Chalermprakiat Building, 420/6 Rajvithi Road, Bangkok 10400, Thailand.
} 
Received: 12 July 2017 Accepted: 18 December 2017

Published online: 08 January 2018

\section{References}

1. Thornhill S. Disability in young people and adults one year after head injury: prospective cohort study. BMJ. 2000;320(7250):1631-5.

2. Shukla D, Devi Bl, Agrawal A. Outcome measures for traumatic brain injury. Clin Neurol Neurosurg. 2011;113:435-41.

3. Dhandapani SS, Manju D, Mahapatra AK. The economic divide in outcome following severe head injury. Asian journal of neurosurgery. 2012;7:17-20.

4. Deb S, Lyons I, Koutzoukis C. Neuropsychiatric sequelae one year after a minor head injury. Journal of Neurol Neurosurg Psychiatry. 1998;65(6):899-902.

5. Levin HS, Grossman RG. Behavioral sequelae of closed head injury. Archives Neurology. 1978;35:720-7.

6. De Silva MJ, Roberts I, Perel P, Edwards P, Kenward MG, Fernandes J, Shakur $\mathrm{H}$, et al. Patient outcome after traumatic brain injury in high, middle and low-income countries: analysis of data on 8927 patients in 46 countries. Int J Epidemiol. 2009:38(2):452-8.

7. Zhu P, Jiang J. Employment of trauma and injury severity score and a severity characterization of trauma in the outcome evaluation of trauma care and their research advances. Chinese Medical Journal. 1998;111(2):169-73.

8. Champion HR, Copes WS, Sacco WJ, Lawnick MM, Bain LW, Gann DS, Gennarelli T, et al. A new characterization of injury severity. J Trauma. 1990; 30(5):539-46.

9. Rabbani A, Moini M. Application of "trauma and injury severity score" and "a severity characterization of trauma" score to trauma patients in a setting different from "major trauma outcome study.". Archives of Iranian medicine. 2007:10(3):383-6.

10. Champion HR, Copes WS, Sacco WJ, Frey CF, Holcroft JW, Hoyt DB, Weigelt JA. Improved predictions from a severity characterization of trauma (ASCOT) over trauma and injury severity score (TRISS): results of an independent evaluation. J Trauma. 1996;40(1):42. -48-49

11. Nwomeh BC, Lowell W, Kable R, Haley K, Ameh EA. History and development of trauma registry: lessons from developed to developing countries. World Journal of Emergency Surgery. 2006:1:32.

12. Fuller A, Tran T, Muhumuza M, Haglund MM. Building neurosurgical capacity in low and middle income countries. eNeurologicalSci. 2016:3:1-6.

13. Veerasingam E. An analysis of outcome of head injury patients admitted to the accident service neuro surgical intensive care unit at the National Hospital of Sri Lanka. Sri Lanka Journal of Anaesthesiology. 2005;13:30-5.

14. O'Neill J, Hibbard MR, Brown M, Jaffe M, Sliwinski M, Vandergoot D, Weiss MJ. The effect of employment on quality of life and community integration after traumatic brain injury. Journal of Head Trauma Rehabilitation. 1998; 13(4):68-79.

15. Whitnall L, McMillan TM, Murray GD, Teasdale GM. Disability in young people and adults after head injury: 5-7 year follow up of a prospective cohort study. Journal of Neurol Neurosurg Psychiatry. 2006;77(5):640-5.

16. Narayan RK, Michel ME, Ansell B, Baethmann A, Biegon A, Bracken MB, Bullock MR, et al. Clinical trials in head injury. J Neurotrauma. 2002; 19(5):503-57.

17. Yates DWABC. Of major trauma. Scoring systems for trauma. BMJ. 1990; 301(6760):1090-4

18. Jennett B, Bond M. Assessment of outcome after severe brain damage. Lancet. 1975:1(7905):480-4.

19. Teasdale GM, Pettigrew LEL, Wilson JTL, Murray G, Jennett B. Analyzing outcome of treatment of severe head injury: a review and update on advancing the use of the Glasgow outcome scale. Journal of Neurotrauma. 1998;15(8):587-97.

20. Wilson JT, Pettigrew LE, Teasdale GM. Structured interviews for the Glasgow outcome scale and the extended Glasgow outcome scale: quidelines for their use. J Neurotrauma. 1998;15(8):573-85

21. Wilson JTL, Slieker FJA, Legrand V, Murray G, Stocchetti N, Maas AIR, Observer variation in the assessment of outcome in traumatic brain injury: experience from a multicenter, international randomized clinical trial. Neurosurgery. 2007:61(1):123-8

22. Bouamra O, Jacques R, Edwards A, Yates DW, Lawrence T, Jenks T, Woodford $\mathrm{M}$, et al. Prediction modelling for trauma using comorbidity and "true" 30-day outcome. Emergency Medical Journal. 2015;32(12):933-8.

23. StataCorp. Stata Data analysis and statistical software, 2017. http://www. stata.com/company/(accessed 01/01/2010).
24. Deepika, A., Devi, B. I., \& Shukla, D. (2017). Predictive validity of disability rating scale in determining functional outcome in patients with severe traumatic brain injury, Neurol India 2017 Jan-Feb;65(1):83-86.

25. Gupta D, Sharma D, Kannan N, Prapruettham S, Mock C, Wang J, et al. Guideline adherence and outcomes in severe adult traumatic brain injury for the CHIRAG (collaborative head injury and guidelines) study. World Neurosurgery. 2016;89:169-79. https://doi.org/10.1016/j.wneu.2015.12.097

26. Haniffa R, et al. Applicability of APACHE II model to a low middle income country setting. Under review Journal of Critical Care.

27. Williams TA, Leslie GD. Challenges and possible solutions for long-term follow-up of patients surviving critical illness. Australian Critical Care 2011; 24(3):175-185.

28. Rahuman M, Jayawardana J, Francis G, Niraj M, Kumara A, Wijesinghe U, Haniffa R, et al. Outcome of early coronary intervention for acute ST elevation myocardial infarction in a tertiary care cardiac centre in Sri Lanka. Ceylon Med J. 2016;61(12015):26-31.

29. Vassar MJ, Lewis FR, Chambers JA, Mullins RJ, O'Brien PE, Weigelt JA, Hoang MT, et al. Prediction of outcome in intensive care unit trauma patients: a multicenter study of acute physiology and chronic health evaluation (APACHE), trauma and injury severity score (TRISS), and a 24-hour intensive care unit (ICU) point system. Journal of Trauma-Injury Infection \& Critical Care. 1999:47:324-9.

30. Haniffa et al. Applicability of APACHE II in a Lower Middle Income Country. J Crit Care. 2017:"under review.

31. Hosmer DW, Lemeshow S. Applied logistic regression second edition. Applied Logistic Regression. 2004;392

32. Gunaratne A, Wadanambi S. An audit on admission of patients with head injury to teaching hospital Karapitiya, Galle. Sri Lankan Journal of Anaesthesiology. 2009;17(2):51-4.

33. Hyder AA, Wunderlich CA, Puvanachandra P, Gururaj GKO. The impact of traumatic brain injuries: a global perspective. NeuroRehabilitation. 2007; 22(5):341-53.

34. Balestreri M, Czosnyka M, Chatfield DA, Steiner LA, Schmidt EA, Smielewsk $P$, et al. Predictive value of Glasgow coma scale after brain trauma: change in trend over the past ten years. J NeurolNeurosurg Psychiatry. 2004;75:1612. http://jnnp.bmj.com/content/75/1/161.long

35. Majdan M, Brazinova A, Rusnak M, Leitgeb J. Outcome prediction after traumatic brain injury: comparison of the performance of routinely used severity scores and multivariable prognostic models. Journal of Neurosciences in Rural Practice. 2017;8(1):20-9. https://doi.org/10.4103/0976-3147.193543.

\section{Submit your next manuscript to BioMed Central and we will help you at every step:}

- We accept pre-submission inquiries

- Our selector tool helps you to find the most relevant journal

- We provide round the clock customer support

- Convenient online submission

- Thorough peer review

- Inclusion in PubMed and all major indexing services

- Maximum visibility for your research

Submit your manuscript at www.biomedcentral.com/submit
) Biomed Central 